\title{
Compaction of granular graphite in a vertically vibrating container with restricted geometry
}

\author{
O.I.Gerasimov ${ }^{1}$, V.A.Idomskyy ${ }^{1}$, P.P.-J.M.Schram ${ }^{2}$ \\ 1 Hydrometheorological Institute, Department of General Physics, \\ 15 Lvivska Str., 65116 Odessa, Ukraine \\ 2 Eindhoven University of Technology, Department of Technical Physics, the \\ Netherlands
}

\begin{abstract}
Received August 8, 2000
The compaction of vertically vibrating granular materials (highly dissipative media composed of macroscopic grains that interact by means of contact forces) with restricted geometry is examined stroboscopically. Possible interpretation of the observed picture of compaction is discussed in particular by means of the nonequilibrium (nonergodic) states predicted in hydrodynamics of one-dimensional system of inelastic particles [1] as well as described in dynamics of 1D chemically reacted lattice model [2-5].
\end{abstract}

Key words: granular materials, nonequilibrium states, one-dimensional models

PACS: $81.05 . R m, 61.50 . A h, 64.60 . C n$

\section{Introduction}

Granular systems are complex classical many-particle systems; their complexity results from the fact that the grains are finitely extensed, can have complicated shapes, interact only through friction and inelastic collision, and compact due to gravity. Shaking can compact the system. However, the question how the compaction happens and develops is a highly nontrivial problem [6]. Suffice it to say that compaction due to shaking is the property that does not appear in solids or Newtonian fluids and therefore, standard approaches, for example, using the equation of state, fail. This happens because granular systems show dynamical features that belong to almost unexplored field of compressible viscoelastic fluids, often called soft matter. In the presented paper we consider the particular question of some features of compaction of a dry granular system that is put in vertically vibrating capillary

*E-mail: ogerasimov@paco.net 


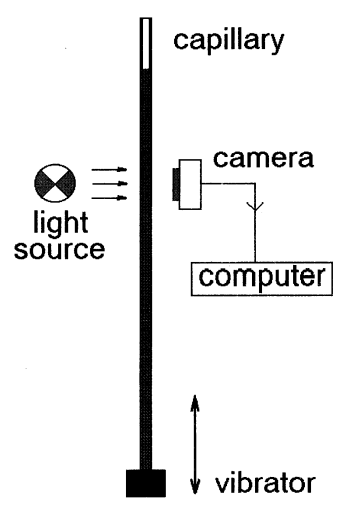

Figure 1. The schematic experimental setup.
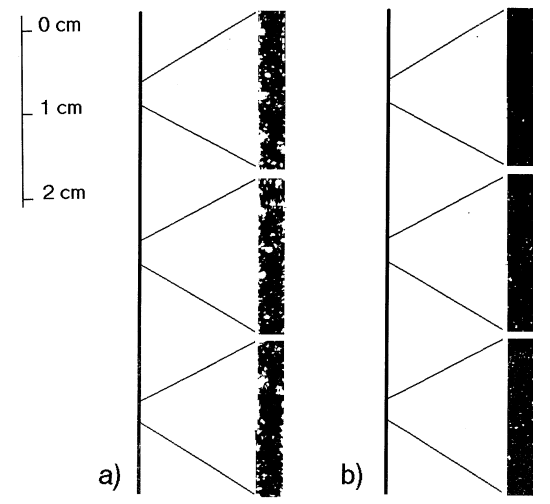

Figure 2. The resulting picture of the compaction.

container constructed using two parallel glass windows. The picture of compaction of the grains has been observed visually by means of stroboscopic test. The density of grains demonstrates the specific type of compaction which is typical neither for three-dimensional nor for two-dimensional systems. The possible dynamical scenarios that lead to considering the granular systems in the capillaries as quasi-one dimensional ones with a special nonequilibrium (metastable) states, predicted earlier in one-dimensional dissipative hydrodynamics by L.Kadanoff [1] as well as described with the model dynamics in one-dimensional chemically reacted systems on lattices by G.Nicolis and one of the authors (O.I.G.) [2,5], have been discussed.

\section{Method of experiment}

The experimental setup is described schematically in figure 1. We fill in a vertical rectangular glass capillary $100 \mathrm{~mm}$ long with dry granular graphite with granular dispersion measuring $\lambda=0.3 \div 0.4 \mathrm{~mm}$. The tube is connected with the vibrator (which plays the role of a loudspeaker). We use a photo camera (see figure 1) to observe the picture of the dry granular system compaction that happens due to shaking.

\section{Results and conclusions}

The resulting picture of the compaction is shown in figure 2 (the dark zone corresponds to higher density of granules). As one can see, the nontrivial compaction of vertically vibrating granules in the capillary takes place. Namely, the upper part of capillary includes definitely a more compact fraction of the investigated system than the lower part does. This picture contradicts the trivial scenario of Boltzman compaction of many-particle systems in the presence of gravity. The nonuniform character of the compaction in one-dimensional system of inelastic particles has been studied in [1] within the hydrodynamic approach. It was shown that the majority of the particles (constrained to move on a line with energy input from the 
boundaries) get clumped into a small region of space and move with very slow velocities (i.e., we have a closely compacted subsystem). The remaining particles travel between the boundaries (i.e., with a relatively large scale) at much higher speeds (creating the subsystem with low compaction). Such a state (which leads to a respective non-uniform compaction) clearly violates equipartition of energy. It has been observed that the particles collide with each other and the initial kinetic energy gets dissipated after a transient period so that eventually the system ends up to the same final state as described above. The system with the various number of particles $\mathrm{N}$ and with the various value of a restitution coefficient $\varepsilon$ (with $\mathrm{N}_{\varepsilon}\langle 1$ ) has been simulated. Moreover, it has been shown that the formation of inhomogeneity zones (clamps) does not disappear as $\varepsilon \rightarrow 0$ (contrary to the prediction of the hydrodynamic equations) and the particles in the clump get squeezed into a smaller space and move with slower speeds with fixed $N$ and decreasing $\varepsilon$. The situation is certainly completely different if we take perfectly elastic particles. The collision between two particles simply causes the exchange of their velocities. After a while, the initial velocity of any particle will be given to the leftmost one and get randomalized by the collision with he wall. Thus, the system will eventually reach the state where the particles distribute themselves uniformly in space, with velocities assuming the Gaussian distribution. We should emphasize that such extraordinary states have probably been observed in the model nonlinear chemical dynamics in low dimensions. In particular in [2-5] it has been shown that restricting space to low dimensions can cause deviations from the mean-field behaviour in certain statistical systems such as perfect lattices totally or fragmentially filled. In one dimension, the produced exact results show that the trimolecular reaction system stabilizes in a nonequilibrium, locally, frozen asymptotic state in which ratio $\mathrm{r}$ of one to another sort of particles is a constant number $r=0.38$, quite different from the mean field ratio, $r_{\mathrm{MF}}=1$. At the same time, the bimolecular chemical reaction is shown to agree with the mean field predictions. It was also shown that the adoption of certain types of transition rules in the laws of evolution can lead to oscillatory steady states. To investigate, the compaction of dry granular systems within the restricted geometry we use the carbon granules with the size dispersion $\lambda \sim 0.3 \div 0.4 \mathrm{~mm}$ that were put in the narrow rectangular capillary with the cross section $\sigma \sim 0.5 \mathrm{~mm}$. Thus, the ratio $\gamma=\sigma / \lambda \varepsilon$ and system rigorously speaking could not be considered as one dimensional. But because of complex shape morphology of granules, the ratio $\gamma$ could be considered effectively close to 1 . Furthermore, one can imagine that the provided reason of an extraordinary compactization which has been stroboscopically observed in those systems is the formation of a special dynamical dissipative mode of their behaviour with a restricted geometry. In [7] the stroboscopic compaction of the dynamics of dry granular systems has been studied as a function of time step. The logarithmic decay of the compaction ratio has been found. A simple nonlinear model for the dynamics from shake to shake which is based on viscoelastic ideas and leads to the observed stroboscopic map has been proposed. At present no quantitative experimental results on the density profile of the decomposition and recompaction stroboscopic map (or stationary states) are definitely available 
in literature. Therefore the qualitative modeling as well as respective speculations are promptly required in order to formalize and to quantify the compaction of dry granular systems. Special interest should be paid to the investigation of stationary modes in vibrated granular systems that probably exist. We will investigate this subject elsewhere [8].

\title{
References
}

1. Du Y., Li H., Kadanoff L. // Phys. Rev. Lett., 1995, vol. 74, p. 1268.

2. Provata A., Turner J.W., Nicolis G. // Journ. Stat. Phys., 1993, vol. 70, p. 1195.

3. Gerasimov O., Nicolis G. // Journ. Cond. Matt., 1999, vol. 2, p. 75.

4. Gerasimov O., Nicolis G. Structure factor of 1D chemically reacted system on a lattices. Proceedings of NATO ASI, Leden, 1998.

5. Herrmann H.J. Computer Simulations of Granular Media in Disorder and Granular Media (ed. D. Bideau, A. Hansen). Elsevier, 1993.

6. Linz S.J. Phenomenological modeling of compaction dynamics of shaken granular systems. // Phys. Rew. E., 1996, vol. 54, No. 3, p. 2925-2930.

7. Gerasimov O., Nicolis G. Nonlinear chemical dynamics within the restricted geometry. - In: Abstracts of Statphys. XX International Conference, Paris, Sorbonne, 1998.

8. Gerasimov O., Spivak A. Stationary states in model 1D system of inelastic particles. // Ukranian Journ. of Phys. (in press).

\section{Ущільнення гранульованого графіту у вертикально вібруючому контейнері з обмеженою геометрією}

\author{
О.І.Герасімов ${ }^{1}$, В.А.Ідомський ${ }^{1}$, П.П.-Дж.М.Шрам ${ }^{2}$ \\ 1 Гідрометеорологічний інститут, 65116 Одеса, вул. Львівська, 15 \\ 2 Університет технології м. Ейндговена, \\ Голандія
}

Отримано 8 серпня 2000 р.

Вивчаються стробоскопічно ущільнення вертикально вібруючих гранульованих матеріалів (високо дисипативного середовища, що складається з макроскопічних зерен, взаємодіючих контактно) з обмеженою геометрією. Можлива інтерпретація спостережуваної картини обговорюється, зокрема, з допомогою нерівноважних (неергодичних) станів, передбачених в гідродинаміці одновимірних систем нееластичних частинок [1] і описаних в динаміці одновимірної хімічноактивної граткової моделі [2-5].

Ключові слова: гранульовані матеріали, нерівноважні стани, одновимірні моделі

PACS: $81.05 . R m, 61.50 . A h, 64.60 . C n$ 